\title{
Banking Underserved Market Segments
}

\author{
Margherita Mori \\ Department of Industrial and Information Engineering and of Economics, University of L'Aquila, L'Aquila, Italy \\ Email: margherita.mori@univaq.it
}

How to cite this paper: Mori, M. (2019) Banking Underserved Market Segments. Open Journal of Social Sciences, 7, 506-517. https://doi.org/10.4236/jss.2019.73042

Received: November 3, 2019

Accepted: March 26, 2019

Published: March 29, 2019

\begin{abstract}
This paper aims at discussing how to contribute to sustainable development by targeting underbanked market segments: according to a common view, they include people who have become blacklisted by major banks, are young consumers, want to avoid debt collectors, are fed-up with fees, are out of a job or had a bad customer experience; in these cases, traditional financial services could—or would-be hardly accessed and informal channels tend to prevail. The unbanked too call for attention, as that they do not even hold a bank account and hence are excluded from formal banking opportunities, which is likely to pave the way to alternative, less reputable business models. Given the high number of potential consumers involved worldwide, furthering their financial inclusion sounds like a must. In sight of reaching this ambitious goal, the starting point can be identified with an extensive analysis of the underlying concepts, that are closely linked to the Sustainable Development Goals adopted by the United Nations in 2015; the next step revolves around the features of the market segments under investigation, their financial needs that remain unsatisfied and the strategic tools that are likely to improve the state of the art. The main findings lead to stress that usually listed categories to be better served by banks do not tell the whole story, which should act as a stimulus to disseminate best practices and to suggest concrete proposals; they can help to meet the critical challenges of social and economic sustainability within the framework of the generation pact and may also allow financial institutions to expand their activity profitably. Conclusions imply that a more inclusive financial system would provide benefits to the underbanked (not to mention the unbanked), as well as to society at large, with financial competence, literacy and education set to gain momentum.
\end{abstract}

\section{Keywords}

Financial Inclusion, Financial Sustainability, Sustainable Development, Unbanked People, Underbanked Households 


\section{Introduction}

Millions and millions of consumers can be labelled as "underbanked", not only in fragile areas but also in industrialized countries, and surveys are likely to underestimate such a disappointing situation: it is due to both supply and demand factors resulting in a limited provision of financial services to the market segments that can be devised accordingly and that include both households and firms, mostly micro- and small-sized enterprises; to make things worse, a significant share of the world population is said "unbanked", thus leading to shed light on people who do not even have their own bank accounts and often resort to expensive check-cashing services. For sure, this scenario is not consistent with the Sustainable Development Goals (SDGs) that have been adopted by the United Nations (UN) in 2015 while setting the "2030 Agenda" [1] and that seek to complete what the Millennium Development Goals did not achieve, particularly in reaching the most vulnerable.

Challenges ahead are conditioned upon the gap to be filled in terms of financial inclusion, which does not apply to usually listed market segments only, since unprecedented needs emerge from evolutionary trends (such as those that refer to migration flows and to an aging population). Yet, the ideal link between sustainability and inclusiveness has been emphasized in many international for a: along this pathway, a comprehensive set of policy actions was put together in the "Addis Ababa Action Agenda" (AAAA) that the UN also agreed upon in 2015 and that was conceived to move from billions in financing commitments to trillions, with a package of over 100 concrete measures designed to finance sustainable development and develop sustainable finance; the opportunity came from the Third International Conference on Financing for Development that addressed cross-cultural issues, such as those concerning domestic and international finance, international cooperation and trade as an engine for development, debt and debt sustainability.

This paper takes inspiration from these concepts and aims at providing a framework for analysis that can hopefully contribute to a more inclusive financial system in a global-scale context: improving financial inclusion of the underbanked-not to mention the unbanked-is a must, not just an option, if sustainable development is to be pursuit, to the benefit not only of those who need to be better served by banks and other financial institutions but also of society at large. Conclusions encompass best practices that can be replicated and factual proposals that are likely to prove successful.

\section{The State of the Art}

\subsection{Relevant Goals in the "2030 Agenda"}

A quick look at the "2030 Agenda" is enough to grasp statements of special interest in sight of furthering financial inclusion. It is not a case that the 17 SDGs deal with economic growth, sustainable communities, reduced inequalities, industry, innovation and infrastructure, as well as multi-stakeholder partnerships 
aimed at mobilizing and sharing knowledge, expertise, technology and financial resources; all of these goals have been associated with specific targets to be achieved in the 15 years covered by this document and are supported by a set of actions that can be taken in everyday life as a contribution to a better world.

Details should not be minimized. Goal 8 involving economic growth spells out that it must be inclusive and sustainable, just like industrialization (Goal 9), cities and communities (Goal 11); financial inclusion is evoked whereby policies to be adopted are listed, based on the commitment to improvements towards this end, and - to better define it - the description of Goal 1 ("end poverty in all its forms everywhere") is set to ensure equal access for everybody, "in particular the poor and the vulnerable", to "appropriate financial services, including microfinance".

For the SDGs to be fulfilled, everybody should get involved and financial institutions make no exception. Not to leave anything unattended, the agenda under investigation has acknowledged the need to upgrade the legislation applicable to them, as well as to better regulate financial markets: for instance, the mobilization of financial assistance could reportedly allow "to strengthen developing countries' scientific, technological and innovative capacities to move towards more sustainable patterns of consumption and production"; furthermore, it has been made clear the commitment to "strengthen the capacity of domestic financial institutions to encourage and expand access to banking, insurance and financial services for all" (Goal 8 again).

\subsection{Insights into "Europe 2020"}

Even before the adoption of these goals, the terms "sustainable" and "inclusive" had been jointly highlighted by forging "Europe 2020", the strategic agenda that was launched by the European Commission (EC) in 2010 [2]. In this case, three mutually reinforcing priorities had been identified, that call for smart, sustainable and inclusive growth; they had been selected to help Europe come out stronger from the financial crisis that started in 2007 in the United States and rapidly spread elsewhere.

By "sustainable growth" it is meant the promotion of "a more resource efficient, greener and more competitive economy"; "inclusive growth" fosters "a high-employment economy delivering economic, social and territorial cohesion". To complete the picture, "smart growth" is centered upon "developing an economy based on knowledge and innovation".

The economic perspective should not overshadow the financial one. Actually, this agenda recognizes that "the availability of easy credit, short-termism and excessive risk-taking in financial markets around the world fueled speculative behavior, giving rise to bubble-driven growth and important unbalances" during the global financial crisis that has not exhausted its negative repercussions yet; therefore, "Europe is engaged in finding global solutions to bring about an efficient and sustainable financial system". 


\subsection{Pursuing Sustainable Finance}

The key role that financial institutions keep playing to support the real sphere of the economy sounds like an incentive to pay no less attention to the concepts of "sustainable" and "inclusive finance". Not surprisingly, sustainable finance is looked at by stressing the imperative of improving its "contribution to sustainable and inclusive growth, in particular funding society's long-term needs for innovation and infrastructure" [3]; in a few words, the concept of "sustainable finance" is defined in terms of "the provision of finance to investments taking into account environmental, social and governance considerations" [4].

Environmental considerations have to do with the strong green finance component that can foster a sustainable growth path, as implied by the move to re-orient investments towards more sustainable businesses; governance considerations draw upon an increasing awareness of the risks that may affect the sustainability of the financial system and are closely tied to the need for mitigation strategies through appropriate governance. Environmental challenges and sustainability risks have prompted the EC to establish the High-Level Expert Group on Sustainable Finance on December 22, 2016 in order to rely on specialized advice and recommendations on developing a comprehensive strategy on sustainable finance in the European Union (EU).

As far as social considerations, once again useful insights are provided by the global development community. In spite of the controversial issues that the financial arena has been pervaded by in the last decade, it must be stressed that finance still performs essential functions, encompassing risk management and inter-temporal consumption smoothing; these activities allow households and enterprises to reap benefits that range from managing day-to-day resources to taking advantage of investment opportunities, to mention the most relevant needs satisfied by banks and other financial institutions.

\subsection{Towards a More Inclusive Financial System}

The conceptual thoughts that have been outlined so far lead to focus on financial inclusion: it "means that individuals and enterprises can access and use a range of appropriate and responsibly provided financial services offered in a well-regulated environment", according to the UN Capital Development Fund (UNCDF) [5]; a closely linked viewpoint emphasizes financial resilience as the declared, feasible capacity to survive financial shocks and to obtain money for unexpected expenses. To sum up, "inclusive finance strives to enhance access to financial services for both individuals and micro-, small and medium-sized enterprises" [6], as a way to reduce poverty, tackle inequality and foster growth.

Actually, there is remarkable empirical evidence that suggests a clear relationship between improved access to finance and reduced income inequality and poverty; as such, a more inclusive financial system can be said not only pro-growth but also pro-poor, which requests to devote compounded energies to developing countries. There, more than anywhere else, access to financial ser- 
vices is crucial to strengthen the financial sector, as well as to improve the process of domestic resource mobilization, and higher levels of financial inclusion can spur social and economic development.

For the best results to be scored, despite some criticism [7], an increasingly shared view aims at promoting a more inclusive financial system worldwide by intensifying outreach to marginalized groups, including the poorer strata of the population (especially women), as well as by providing tailored financial services to enterprises at the bottom of the economic pyramid. To this end, the set of strategic tools to be used includes the extension of savings, credit, insurance and payment services, particularly when the amount involved is relatively small; as far as the supply of these services, it comes natural to think about microfinance institutions, though their standard operating model has not met most optimistic expectations [8], but traditional financial intermediaries can be expected to further participate in the joint efforts that are needed.

\subsection{Banks and the Creation of Shared Value}

Within the financial industry, banks are well positioned to make a significant contribution by stimulating more sustainable approaches to business and-in general terms-by promoting the creation of shared value. Undeniably, non-banks competitors have increasingly challenged the banking system that by the way remains essential to foster growth in every economic sector, to finance housing and education and to enable the development of tomorrow's clean energy infrastructure, to account for just a few key functions; nonetheless, shared value opportunities should be pursued more aggressively.

The pivotal role that banks continue to play should allow and persuade them to actively promote the advancement of economic and social conditions in the area in which they are located-and ultimately in our global village as a whole-while developing policies and operating practices that enhance their competitiveness: although some authors contest the value of creating shared value [9], it could be hardly rejected that banking for maximizing returns to stockholders and furthering customer prosperity should be properly integrated with funding the growth of regional economies and financing solutions to global problems.

If some positive effects are to be attributed to the recent financial crisis, a strong stimulus to banking on shared value is one of them, possibly the most relevant. As a consequence, it is no longer time to deliver benefits that only a small elite group is likely to take advantage from and the banking industry should more explicitly recognize the immense potential of generating business by creating societal value in several ways; they can be summarized in terms of "reconceiving products and markets", "redefining productivity in the value chain" and "building supportive industry clusters at the company's locations" [10].

\section{From Theory to Practice}

\subsection{Targeting the Unbanked and Underbanked}

Despite being shared value widely considered a strategic imperative for banks, 
leveraging its full power still requires a significant shift from the way in which the majority of these institutions is currently run. If it is true-as it is-that they are supposed to get closer to society, the priority list should encompass unprecedented efforts to better satisfy the needs of a remarkable share of the population: according to reliable estimates [11], two billions adults-more than half of those who work in the world-are unbanked, which means that they do not even hold a bank account and use alternative financial services, if and where available; these features are most acute among low-income people in emerging and developing economies, though surveys by the Federal Deposit Insurance Corporation show that the United States too suffers from disappointing findings as far as the recourse to banking services by households, especially those with volatile income.

Serious worries also stem from the market segments that fall within the definition of underbanked consumers: according to a recurrent view, they include people who have become blacklisted by major banks, are young consumers, want to avoid debt collectors, are fed-up with fees, are out of a job or had a bad customer experience (such as those who had to cope with a banking crisis); these people avail themselves of banks only on a very limited basis and tend to rely on cash rather than resorting to checks, credit cards and other products that are usually made available through the banking system. Quite common cases involve poor adults who do not trust banks or cannot afford the costs associated with checking accounts, though the use of cashiers' checks to pay bills could hardly end up with proving an efficient behavior.

What fuels feelings of optimism is the growing concern among banks on how to customize their services for underbanked and unbanked households and businesses (especially micro- and small-sized enterprises) in an attempt at maximizing the share of the fully banked. Targeting underserved bank customers sounds like a glocal co-opetitive challenge that-as such-implies a combination of local and global dimensions, as well as of competitive and cooperative issues, and that can benefit from a three-pillared approach: the first pillar is built upon consumer protection regulation and supervision by financial authorities, particularly on transparency and other aspects of market conduct; the second pillar has to do with strategic measures taken either individually or collectively and shaped by principles, standards, codes of conduct and guidelines, whereas the last pillar is centered upon enhanced financial capability of consumers, so as to make sound financial decisions and protect themselves from harm.

\subsection{Evidence from the Banking Industry}

It is therefore appreciable that more and more initiatives focused on the financial footprint of several SDGs have been developed at both national and international level: success stories include the "Financial Education in Schools" program that is run by Italy's Central Bank in line with international best practices [12]; in addition, it has released a series of videos-entitled "Economy and finance-it's never too late" - to foster financial education among adults by cov- 
ering a wide variety of topics, such as investment risk and yield, wealth and indebtedness, insurance companies and pension funds [13]. Institutional initiatives towards similar targets have been launched in many other countries, as shown by the activities performed by the Financial Literacy and Education Commission, established in the United States under the Fair and Accurate Credit Transactions Act of 2003, and by the National Centre for Financial Education that has been set up in India to implement the country's National Strategy for Financial Education.

Meanwhile, a growing number of banks have started to leverage their biggest asset - their core business - to address some of the world's toughest challenges and are realigning their activities to deliver shared value. Efforts to capitalize on new opportunities encompass those that pertain to the "EduCare Project" within the framework of sustainable development strategies of the BNP Paribas Group in Italy: the aim is to contribute to inclusive and quality education, as well as to promote lifelong learning, as implied by UN Goal 4; this initiative has been developed by investing in BNL's free training courses in financial education that are offered to encourage greater awareness of the various personal choices [14].

It is also worth mentioning the project denominated "Banking the Unbanked" that has been undertaken by Bank of Alexandria SAE-shortly Alex Bank, the Egyptian subsidiary of Intesa Sanpaolo Group-and that allows for three integrated lines of intervention aimed at customers who would have no access to traditional banking, in order to improve their living and working conditions: micro-deposits, that include new products at attractive rates, to encourage the culture of saving, and a dedicated debit card; expansion of micro business with a network of local supporting specialists; the creation of a mobile wallet platform for simple and safe banking transactions [15]. Furthermore, this Group has taken part in the "Loan for Hope" initiative that was launched in 2010 by the Italian Episcopal Conference in cooperation with the Italian Banking Association and that was renewed in 2015, in order to support households in temporary difficulties with "social microfinance", while "business microfinance" is dedicated to start-up businesses, young entrepreneurs and in more general terms to smalland micro-sized enterprises [16].

\subsection{Developments under Way}

Attempts at aligning customer prosperity and bank success with local and global growth raise issues that lead to emphasize the distinction between financial products and financial intermediaries, based on the provocative statement that "banking is necessary, banks are not", as cited in [17]. In spite of this questionable viewpoint, that anyway is all but universally endorsed, a more intensive cooperation should be promoted among banks, as well as between them and the private sector, in sight of achieving the 17 SDGs and especially fighting financial exclusion; to make a long story short, commercial banks should get more and more involved in this evolutionary scenario though other institutions in the banking industry would have no excuses to stay behind the scene. 
For instance, national and multilateral development banks can be considered instrumental in creating robust credit markets in emerging economies and thus promoting sustainable development: new products could be supplied by these banks for them to take on risks that the private sector is reluctant to bear; it can also be supported to become more comfortable when entering into a public-private partnership, provided that the institutions under scrutiny are close to decision-makers and have a deep understanding of the local political landscape. Not surprisingly, the significant potential of multilateral development banks was recognized upon forging the AAAA and talks have been under way for years to rethink the role of national development banks.

Forward steps need to be favored by specific legislation too. A case in point has to do with the 1996 Debt Collection Improvement Act, that was enacted into a US federal law on April 26, 1996 (Public Law 104 - 134) and that paved the way to turning to prepaid cards to disburse payments to individuals: the benefits to the recipients without a bank account need no comments; conversely, the Treasury Department has been able to save on each payment made electronically rather than by check and ultimately has taken advantage of the migration to all-electronic disbursement of federal benefits.

\subsection{Redefining the Target Market}

In an attempt at banking underserved market segments, it sounds appropriate to go beyond traditional keys of classification, as emerging trends suggest. Here it suffices to recommend a closer look at the implications of migratory flows and of an aging population, so as to highlight the financial needs of consumers who have been overlooked for a long time: on one hand, there are undisputable reasons to account for those who miss relevant documents, do not have a credit history or even lack a permanent address, not only in rural but also in urban communities, but need to be banked, for instance through remittances; recurrent cases surface among recent immigrants and refugees, who have low income (or no money at all) and consequently could not put together the minimum balance to be allowed to open checking and savings accounts.

On the other hand, people in the later stage of their life cycle may not be able to benefit from safe and cost-effective access to financial services that can ensure quality of life and aging with dignity: it is not only a matter of targeting the older who live at or below the poverty level and who are unlikely to use traditional financial services, such as checking, savings, money market or retirement accounts; apart from issues concerning economically vulnerable older people, innovative strategies and products should be developed to better meet the financial needs of affluent senior citizens, as shown by the growing interest in reverse mortgages as a lifetime income planning tool. To stress this point, increasing access to-and participation in-appropriate, responsible and asset-building financial services for the growing market that consists of older people should cover their peak retirement savings years, when being unbanked or underbanked can often mean the difference between poverty and a secure future [18]. 
To draw a more comprehensive picture, special thoughts should be dedicated to differently-abled people (such as wheelchair-bound and visually-impaired persons) who need customized barrier-free access to banks and their products: everybody would be ready to express thoughts against discrimination, both legally and morally, but it still abounds. As such, it sounds consoling that Italy's Museum of Saving launched in July 2018 a competition of ideas-in cooperation with Intesa Sanpaolo Innovation Center and Fondazione La Stampa Specchiodei Tempi-to promote the development of solutions aimed at fostering economic autonomy of people with cognitive disabilities aged between 6 and 99, thus improving financial inclusion of these consumers by addressing their specific needs, with the utmost attention to accessibility, language and communication modes (e.g. using app, podcasts, games and interactive handbooks) [19].

\subsection{Focus on the Marketing Mix}

Besides redefining the target market, there would be no choice but to dynamically reconsider the marketing mix in order to better shape its basic elements that have been historically identified with product, price, promotion and place. Needless to say, the process of financial innovation has provided fruitful support up to now and is set to stimulate further progress within the banking industry and the financial system as a whole: as far as the unbanked and underbanked, their access to finance has been greatly expanded as a result of incremental advances in technology; improvements in this field are usually highlighted with regard to the decreasing costs associated with supplying the financial services traditionally offered by banks and hence to the reduced prices that can be charged to their customers.

At the same time, desirable effects have been-and can still be-generated on how to make consumers (in the first place, the underserved) aware of products that can satisfy their financial needs as a part of the promotional activities carried out by banks, with old ways (such as billboards, word-of-mouth and print ads) being challenged by the internet's myriad innovative methods; positive changes have also been brought about in the distribution channels, with end-users getting more and more familiar with online banking. To the underbanked and unbanked, financial technology (known as fintech) can act as a catalyst for financial inclusion, as shown by lessons learned in rural areas [20], as well as by the results that have been attained while coping with immigrants and refugees [21].

Furthermore, basic bank accounts have been made available in several countries to people who are not eligible for standard current accounts or cannot use their existing accounts due to financial difficulties, as a way to tap the unbanked: supporting arguments include the need to allow underserved market segments to get access to payment services-and eventually loans-through the banking system; it must also be stressed that these people may save in informal ways-such as keeping cash at home and buying illiquid assets, which may be costly, risky, or inconvenient-instead of using banks [22]. Beneficiaries of these 
accounts do not necessarily belong to poorer market segments, as implied by Italy's recent legislation (Decree 70 of May 13, 2018 by the Ministry of Economy and Finance) that was introduced to define applicable costs and standard features.

\section{Conclusions}

To conclude, the SDGs make up a pretty big to-do list that can be expected to drive real transformation in reducing poverty and inequality, thus contributing to put the global economy on track for long-term sustainability. To this end, the post-2015 development agenda should continue to be based on the pursuit of concrete priorities, such as those that can pass the test of being specific, measurable, achievable, relevant and time-bound; inclusive finance stands as a key ingredient to favor a transformative impact that promises to prove rewarding not only to industrialized countries but also to the developing ones.

As far as how to fight financial exclusion, research and education need to be properly combined with practice in order to create a unified foundation for sustainable development: research can be used to inform everyday decisions, public policies and analytical approaches; education stands as a key ingredient in fulfilling the generation pact, which implies the commitment to leave an equally sustainable world - and an even better one-to future generations. Focusing on the financial industry, there is also wide room for directing educational efforts to immigrants, physically challenged people and senior citizens, possibly within the framework of lifelong learning opportunities that may be taken by making recourse to dedicated teaching labs.

While informal and semi-formal channels continue to satisfy financial needs to a considerable extent, especially in fragile and rural areas, banks are called to play once again a pivotal role in an attempt at reducing financial exclusion: despite some criticism, supporting arguments stem from a paradigm shift that has been gaining momentum in the last few years and that fosters banking on shared value. Given the enormous potential of creating social value through retail, commercial and investment banking, these intermediaries can be expected to further contribute to sustainable development by meeting today's challenges, that include better serving the underbanked and targeting unbanked consumers, to the benefit not only of the market segments at issue but to society in a global-scale context.

\section{Conflicts of Interest}

The author declares no conflict of interest regarding the publication of this paper.

\section{References}

[1] UN (2015) Transforming Our World: The 2030 Agenda for Sustainable Development. Resolution Adopted by the General Assembly, New York. 
[2] EC (2010) Communication from the Commission-Europe 2020, March 3, Brussels.

[3] Thimann, C. (2017) Foreword-Financing a Sustainable European Economy. Interim Report by the EU High-Level Expert Group on Sustainable Finance, July, Brussels.

[4] EU (n.d.) Sustainable Finance. EU, Brussels. https://ec.europa.eu/info/business-economy-euro/banking-and-finance/sustainablefinance_en

[5] UNCDF (2016) Financial Inclusion. UNCDF, New York. http://www.uncdf.org/financial-inclusion

[6] Inclusive \& Local Finance (n.d.). http://www.un.org/esa/ffd/topics/inclusive-finance.html

[7] Mader, P. (2017) Contesting Financial Inclusion. https://www.researchgate.net/publication/320226228_Contesting_Financial_Inclusi on

[8] Sherratt, L. (2016) Can Microfinance Work? Oxford University Press, New York. https://doi.org/10.1093/acprof:oso/9780199383191.001.0001

[9] Crane, A., Palazzo, G., Spence, L.J. and Matten, D. (2014) Contesting the Value of “Creating Shared Value". California Management Review, 2, 130-153. https://doi.org/10.1525/cmr.2014.56.2.130

[10] Porter, M.E. and Kramer, M.R. (2011) The Big Idea: Creating Shared Value. https://pdfs.semanticscholar.org/53c0/606a0d6f7d01434039bf7039f8e48f95fd06.pdf(

[11] Demirguc-Kunt, A., Klapper, L., Singer, D. and Van Oudheusden, P. (2015) The Global Findex Database 2014-Measuring Financial Inclusion around the World. World Bank Group, Washington DC. https://doi.org/10.1596/1813-9450-7255

[12] Bank of Italy (2015) The Bank of Italy Launches the 2015/2016 "Financial Education in Schools" Programme.

https://www.bancaditalia.it/media/notizia/the-bank-of-italy-launches-the-2015-201 6-financial-education-in-schools-programmme/?com.dotmarketin\%E2\%80\%A6

[13] Bank of Italy (2017) Collana video "Economia e finanza-non è mai troppo tardi". http://www.bancaditalia.it/media/notizia/collana-video-economia-e-finanza-non-m ai-troppo-tardi/

[14] BNP Paribas (2016) Financial Education for an Educated Choice. http://www.bnpparibas.it/en/bnp-paribas/corporate-social-responsibility/

[15] Bank of Alexandria SAE (n.d.) Creating Shared Value-Driving Financial Inclusivity across Egypt.

https://www.alexbank.com/Cms_Data/Contents/AlexBank/Media/pdf/sustainability -fb.pdf

[16] Intesa Sanpaolo (2018) Financial Inclusion of Vulnerable People-Micro-finance Projects.

http://www.group.intesasanpaolo.com/scriptIsir0/si09/sostenibilita/eng_inclusione_ finanziaria.jsp?tabId=microcredito\&tabParams=eyd0YWJJZCc6J21pY3JvY3J1ZGl0 byd9\#/sostenibilita/eng_inclusione_finanziaria.jsp\%3FtabId\%3Dmicrocredito\%26ta bParams\%3Deyd0YWJJZCc6J21pY3JvY3J1ZGl0byd9

[17] Amberber, E. (2015) Banking Is Necessary, Banks Are Not'-7 Quotes from Bill Gates on Mobile Banking. https://yourstory.com/2015/01/quotes-bill-gates-mobile-banking/

[18] AARP Foundation (2010) A Portrait of Older Underbanked and Unbanked Con- 
sumers-Findings from a National Survey. AARP Foundation, Washington DC. https://assets.aarp.org/rgcenter/ppi/econ-sec/underbank-economic-full-092110.pdf

[19] Press Release (2018) Al via un contest a premi per agevolare l'autonomia economica delle persone con disabilità cognitiva.

www.museodelrisparmio.it/wp-content/uploads/2018/07/Comunicato-Stampa-prog etto-Eureka.pdf

[20] Kearns, A. (2018) 5 Ways Fintech Is Helping the Unbanked and Underbanked Population in 2018. FinTech Weekly.

https://medium.com/fintech-weekly-magazine/5-ways-fintech-is-helping-the-unba nked-and-underbanked-population-in-2018-54f22417d0b1

[21] Campbell, R. (2017) How Finland Is Using Blockchain Technology to Help Unbanked Asylum Seekers. Coin Journal.

https://coinjournal.net/finland-using-blockchain-technology-help-unbanked-asylu m-seekers/

[22] Dupas, P., Karlan, D., Robinson, J. and Ubfal, D. (2018) Banking the Unbanked. Evidence from Three Countries. American Economic Journal: Applied Economics, 4, 257-297. https://doi.org/10.1257/app.20160597 